\title{
MORE HOSPITAL CHOICES, MORE C-SECTIONS: EVIDENCE FROM CHILE
}

\author{
Ramiro de Elejalde
}

Eugenio Giolito

\section{LATIN AMERICAN AND THE CARIBBEAN ECONOMIC ASSOCIATION}

June 2019

The views expressed herein are those of the authors and do not necessarily reflect the views of the Latin American and the Caribbean Economic Association. Research published in this series may include views on policy, but LACEA takes no institutional policy positions.

LACEA working papers are circulated for discussion and comment purposes. Citation of such a paper should account for its provisional character. A revised version may be available directly from the author.

(C) 2019 by Ramiro de Elejalde and Eugenio Giolito. All rights reserved. Short sections of text, not to exceed two paragraphs, may be quoted without explicit permission provided that full credit, including (C) notice, is given to the source. 
LACEA WORKING PAPER SERIES No. 0028 June 2019

More hospital choices, more C-sections: Evidence from Chile

\author{
Ramiro de Elejalde \\ Departamento de Economía, Universidad Alberto Hurtado, Chile \\ rdeelej@uahurtado.cl \\ Eugenio Giolito \\ Departamento de Economía, Universidad Alberto Hurtado, Chile and IZA \\ egiolito@uahurtado.cl
}

\begin{abstract}
In this paper, we study the effect on cesarean rates of a policy change in Chile that decreased the cost of delivery at private hospitals for women with public health insurance. Using a difference-indifferences (DID) approach based on the eligibility conditions for this benefit, we find that in the first three years after the policy took effect, deliveries in private hospitals increased by 8.7 percentage points, while the probability of a C-section being performed increased by 4.6 percentage points, with negative impacts on average newborn weight and size at birth. We show that the probability of an early term birth in hospitals participating in the program is an increasing function of expected hospital demand at the time of the full-term due date. This suggests that in the absence of price incentives, hospitals use $\mathrm{C}$-sections to smooth out demand over time to optimize the use of their resources.
\end{abstract}

JEL Classification: I11, I13, I18.

Keywords: Health care, provider incentives, labor and delivery.

\title{
ACKNOWLEDGEMENTS AND FINANCIAL DISCLOSURE
}

We would like to thank Matías Busso, Olga Namen, Julio Cáceres-Delpiano and María Nieves Valdés for their valuable comments. We also want to thank the seminar participants at Universidad de Chile, Universidad de Santiago de Chile, LACEA-Health 2018, SECHI 2018 and Seventh Workshop in Economic Development. Errors are ours. 


\section{Introduction}

The rate of C-sections has increased worldwide in recent years. According to Betrán et al. (2016), the largest increase in C-section rates has occurred in Latin America and the Caribbean (LAC), where it went from $27 \%$ in 2000 to $42 \%$ in 2014 . Recent studies in several countries suggest a correlation between delivery at for-profit private hospitals and C-sections (for example, see Hoxha et al., 2017). 1 - Figure 1 shows that C-section rates and the number of deliveries in private hospitals in Chile have increased in recent decades. This relationship was first documented qualitatively by Murray (2000), who found that women treated by private obstetricians are more likely to have C-sections than women treated by midwives or doctors in public hospitals. More recently, Borrescio-Higa and Valdés (2018) found an association between high $\mathrm{C}$-section rates and women with health insurance giving birth at private hospitals.

If the correlation between private hospitals and C-sections is causal, the increase in C-section rates may be due to incentives to physicians or hospitals rather than medical conditions of the pregnancy. This deserves attention given the extensive empirical evidence that non-medically indicated C-sections are detrimental to mothers and newborns. For example, using distance from the mothers' homes to hospitals with high and low C-section rates as an instrument for cesarean delivery, Card et al. (2018) found that C-sections increase the frequency of taking newborns to emergency departments, mainly due to respiratory conditions ${ }^{2}$ Using the hour of delivery as an instrument for a C-section, Costa-Ramón et al. (2018) found that non-medically indicated C-sections negatively affect newborn health as measured by Apgar scores ${ }^{3}$

${ }^{1}$ Hoxha et al. (2017) reviewed studies from 1995 to 2016 for six countries (Australia, Brazil, France, Greece, Mexico and the US), and found that the odds of delivery by C-section were 1.41 higher in for-profit hospitals than in non-profit hospitals.

${ }^{2}$ However, they also found that delivery in a hospital with a high C-section rate decreases infant mortality, because of lower death rates for children with predetermined risk factors.

${ }^{3}$ In addition, several papers document that $\mathrm{C}$-sections with cephalic presentation are associated with adverse maternal and newborn outcomes. These papers show a higher risk of morbidity and postpartum infections in the case of the mother (Villar et al., 2007), a higher risk of complications in future pregnancies (Ananth et al. 1997), a higher risk of injury for the newborn (Alexander et al. 2006), and a higher risk of a stay of 7 days or more in neonatal intensive care unit (Villar 


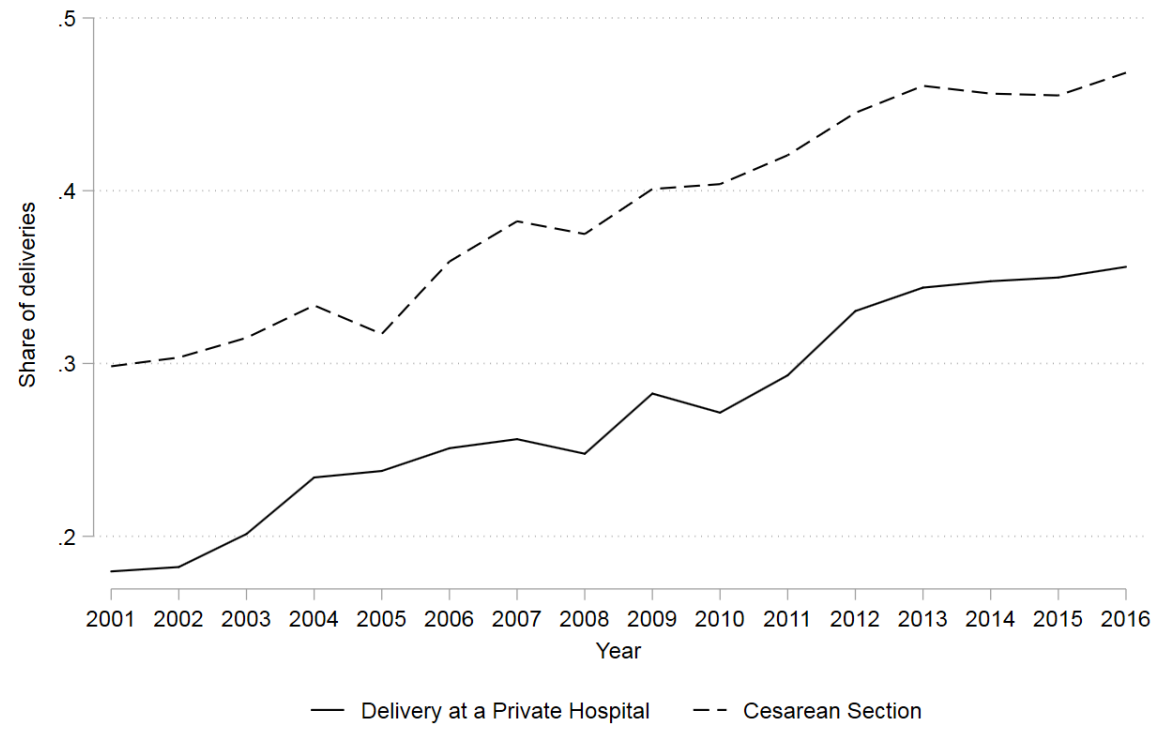

Source: Departamento de Estadísticas e Información de Salud (DEIS), Ministerio de Salud, Chile.

Figure 1: Evolution of the share of deliveries at private hospitals and C-section rates in Chile

In this paper, we study whether a 2003 policy change in Chile that decreased the cost of delivery at private hospitals for women with public health insurance had an effect on cesarean rates, and the potential mechanisms behind this impact. This policy applied to women with public insurance expecting a single baby with a gestational age of 37 weeks or more, except for women with no income. This allowed us to use a difference-in-differences (DID) estimation strategy to measure the impact of the policy on the probability of delivery at a private hospital, the probability of a C-section and the impact of the policy on newborn outcomes of weight and size at birth. We find that during the first 3 years after the policy was introduced, it increased the probability of a delivery at private hospitals by 8.7 percentage points (51\% increase in terms of the sample mean), and the probability of a C-section by 4.6 percentage points (15\% increase). We also find that the policy had a direct impact on newborn outcomes, causing an average decrease of around 20 grams in et al. 2007). For a review of the association between C-sections and health outcomes see Hyde et al. (2012). 
birth weight and of approximately 0.09 centimeters in size at birth.

To find the potential mechanisms behind our results, we have to consider that: (i) public insurance pays private hospitals the same fee for a delivery independent of the mode of delivery (vaginal or cesarean), and (ii) it is more expensive for a private hospital to perform a cesarean delivery than a vaginal delivery. While the above implies that hospitals earn less per delivery with C-sections, a higher percentage of C-sections may allow hospitals to schedule more deliveries and increase aggregate profits via a quantity effect. If this mechanism is at work, private hospitals may use C-sections to smooth out demand over time and thus optimize the use of their resources.

Consistent with the previous explanation, we provide evidence that private hospitals participating in the program (and only those hospitals) are more likely to reschedule a delivery when its theoretical due date at week 40 is a high demand week. We find that the probability of an early term birth (on week 37 or 38) is an increasing function of the expected demand at term, calculated as the number of deliveries that would have reached week 40 at the same time. Moreover, we find that, among those hospitals, the effects hold only for those with high average C-section rates (over 65\%).

Our paper fits within the literature on physician-induced demand, i.e. physicians can influence patient demand to suit their own interests. Specifically, several papers have found that physicians receiving higher fees for C-sections than for vaginal delivery increase the probability of C-section deliveries (for example see Gruber et al. 1999, Allin et al., 2015 and Foo et al., 2017). 4

Our work is also related to research on the effects of the type of hospital on medical outcomes. For example, Johnson and Rehavi (2016) compared C-section rates for HMO-owned hospitals and non-HMO-owned hospitals for physician and non-physician patients, using data for California from 1996-2005. They found that C-section rates for non-physicians are lower in HMO-owned hospitals than in nonHMO-owned hospitals, while C-section rates for physician patients do not depend

${ }^{4}$ Gruber and Owings $(\sqrt{1996)}$ took a different approach and used changes in fertility rates in the US from 1970 to 1982 to estimate the causal effect of decreased demand on the behavior of obstetricians/gynecologists (performing vaginal or C-section delivery). 
on hospital ownership..$^{5}$

This paper makes two main contributions. First, it contributes to the evaluation of a policy that was successful in easing access to private hospitals for women with public insurance. However, this policy increased the C-section rate, and indirectly worsened the well-being of newborns. Second, in contrast to the results of previous literature, our results suggest that hospitals/physicians have incentives to perform a high rate of $\mathrm{C}$-sections although individual procedures may not be the profitmaximizing choice. Therefore, the extent and the mechanisms behind physicianinduced demand may be different, related to the number of procedures rather than price.

The paper is structured as follows. The next section discusses the institutional setting for health care and health insurance in Chile. Section 3 describes the datasets we use in the paper. Section 4 discusses our empirical strategy. Section 5 presents the results for the impact of the policy on the probability of delivery at a private hospital and the probability of a C-section delivery. Section 6 presents the impacts on newborn outcomes. Section 7 analyzes the impacts of expected hospital demand on the timing of births. Finally, Section 8 summarizes the main results.

\section{Institutional Setting}

Health insurance in Chile is mandatory for employees and retirees, but optional for the self-employed and economically inactive individuals. Health insurance buyers can choose between public or private insurance. In 2015, $74 \%$ of the population had public insurance, $19 \%$ had private insurance, and $7 \%$ were uninsured or had special insurance for the police and armed forces.

Private insurance is supplied by private firms called ISAPRES (the Spanish acronym for Institución de Salud Previsional). ISAPRES offer multiple health plans with different combinations of premiums and health coverage. Premiums are riskadjusted by age and gender. Public insurance is administered by the Fondo Nacional de Salud (FONASA), and is financed by a 7\% tax on enrollees' taxable income and

\footnotetext{
${ }^{5}$ Other examples are Shen (2002) and Lien et al. (2008).
} 
government transfers ${ }^{6}$ Individuals with public insurance are assigned to one of four groups: A, B, C or D. Individuals with no income are in group A, those with incomes of less than 360 dollars are in group B, those with incomes between 360 and 530 dollars are in group C, and those with incomes greater than 530 dollars are in group D.7 These groups are important because the coinsurance rate in public hospitals depends on group affiliation: it is zero for individuals in groups A and B, 10\% for individuals in group C, and 20\% for individuals in group D. In 2015, $18 \%$ of the population was in group A, $23 \%$ in B, $13 \%$ in C and $19 \%$ in D.

Historically, public insurance has involved the private provision of medical services. ${ }^{8}$ Specifically, there is a program called Modalidad Libre Elección (MLE) that facilitates access to private hospitals for individuals in groups B, C and D. Under the MLE program, the government sets the hospital fees and copayments for all medical procedures. Private hospitals choose whether or not to participate in the program, and individuals with public insurance can choose from among the available hospitals. For some diagnoses, the MLE program includes the option to use a diagnosis-related group (DRG) payment system called PAD (the Spanish acronym for Pago Asociado a Diagnóstico). Using the PAD system, both the hospital price and the patient's copayment are associated with a diagnosis, irrespective of the actual medical procedures performed.

The most important diagnosis covered in the PAD system is delivery. PAD delivery covers both vaginal and cesarean delivery. Thus, with the PAD delivery, a private hospital receives the same payment independent of the mode of delivery. The PAD delivery covers doctor and midwife fees, hospital stay, medical exams, medication and immunization costs, and postnatal care for 15 days after the patient is discharged. Importantly, to be eligible for a PAD delivery, a woman with public insurance must: (i) be enrolled in group B, C, or D, (ii) expect a single baby, (iii) have a pregnancy with gestational age of 37 weeks or more (at the time of delivery), and (iv) have a non-high-risk pregnancy.

\footnotetext{
${ }^{6}$ The $7 \%$ tax on the enrollee's taxable income is up to a maximum of approximately 200 dollars.

${ }^{7}$ If an individual has more than three dependents, he/she is included in the next group with lower income requirements.

${ }^{8}$ Private health insurance, on the other hand, only provides access to private hospitals, except in special cases like an emergency.
} 


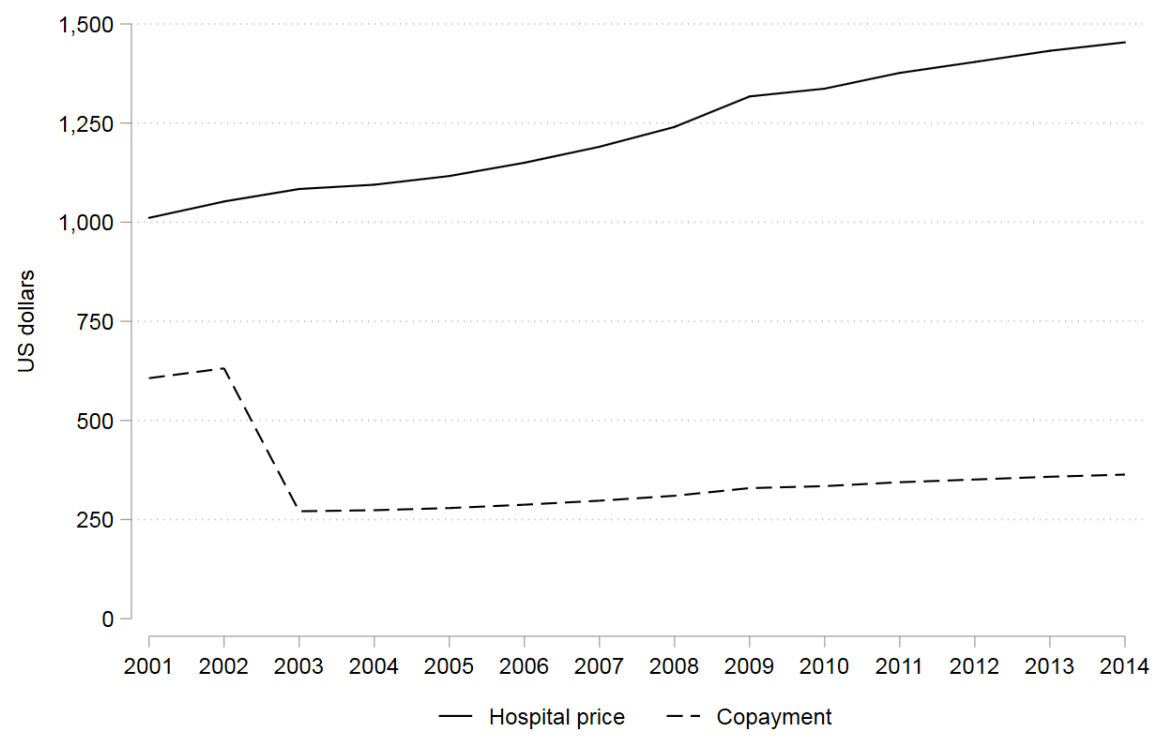

Source: FONASA, Ministerio de Salud, Chile.

Figure 2: Evolution of hospital prices and copayments for PAD delivery

To satisfy these eligibility requirements, on week 37 , a woman must present a medical certificate about her pregnancy risk status to her chosen hospital. Since the high-risk status is loosely defined in the PAD requirements, the hospital can request additional tests for the patient and eventually reject the case. If the hospital accepts the case, the woman pays the copayment and gets PAD coverage.

We study the effect of a significant decrease in the copayment for PAD delivery in 2003. As shown in Figure 2, the copayment for delivery fell from around 630 dollars in 2002 to 270 dollars in $20039^{9}$ In relative terms, PAD delivery users had to pay $60 \%$ of the hospital price in 2002, but only $25 \%$ in 2003 . After this decrease, use of PAD delivery in private hospitals increased from $10 \%$ of deliveries with women in group B, C or D in the first quarter of 2003 to $45 \%$ in the first quarter of 2008 (see Figure 3). In absolute terms, there have been 45,000 PAD deliveries per year since 2008, meaning that one in four deliveries in Chile has been covered by PAD delivery.

An important reason behind the increasing share of deliveries in the private

\footnotetext{
${ }^{9}$ Author's calculation using the exchange rate for February 1, 2019: 657.81 pesos per US dollar.
} 


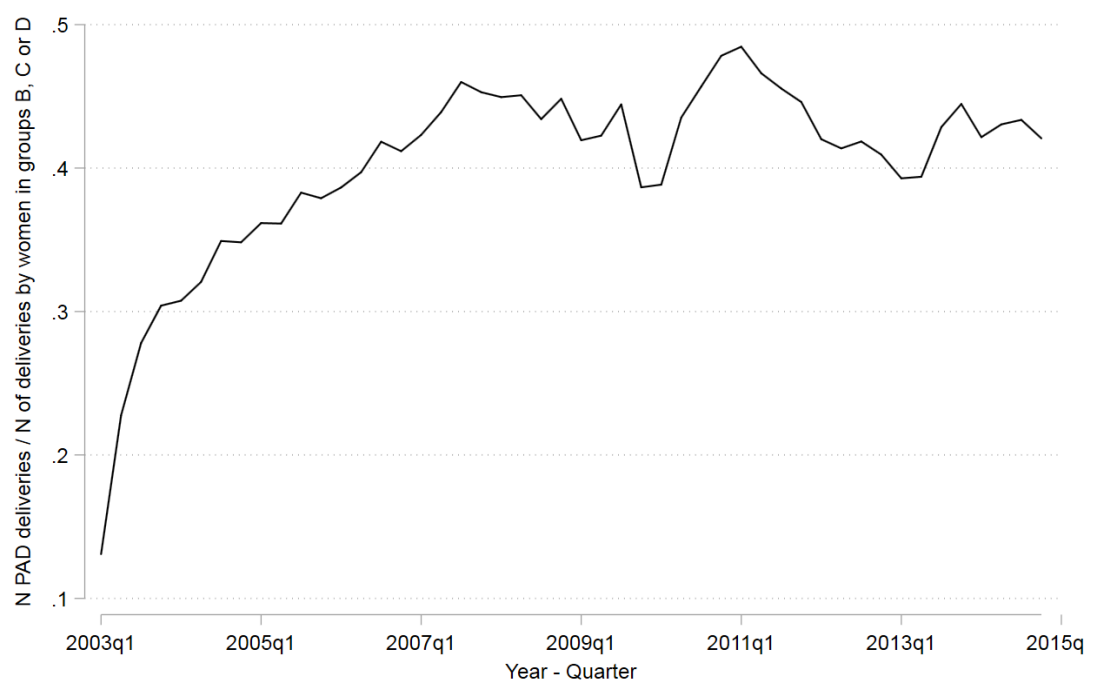

Note: The number of PAD deliveries includes deliveries in private hospitals financed by PAD. Source: FONASA, Ministerio de Salud, Chile.

Figure 3: Share of deliveries by women in public insurance groups B, C or D financed with PAD delivery

sector after the policy change is the perception that medical attention in private hospitals is more personalized than in public hospitals. As Murray and Elston (2005) described, private sector patients can obtain continuity of attention from their personal obstetrician and his/her team for antenatal and postnatal care. In contrast, delivery in the public health system is performed by midwives or doctors on duty, regardless of who provided antenatal care.

\section{$3 \quad$ Data and Descriptive Statistics}

Two public use databases are used in our analysis. First, to estimate the effects of the policy on the probability of delivering at a private hospital and the probability of a C-section, we use Hospital Discharge Data from the Health Statistics and Information Department (DEIS) of the Ministry of Health. All hospitals in Chile must complete a hospital discharge statistical form for every patient discharge, and DEIS collects these data. The hospital discharge dataset is publicly available for the 
period 2001-2016. This dataset includes information on the discharging hospital, the discharge date, length of stay, the main diagnosis code (ICD-10 codes), whether the patient had surgery, and the patients' county of residence, age, gender and type of insurance. We restrict the sample to women between 15 and 47 years of age, giving birth in a hospital, with a hospital stay of fewer than 21 days, during the period 2001-2005 10

We use the ICD-10 codes and whether the patient had surgery to construct the variables vaginal delivery and $\mathrm{C}$-section (see Table 1 for details). We also construct variables to identify the type of hospital. We classify hospitals as public hospitals, private hospitals working with PAD delivery (PAD private hospitals), and private hospitals not working with PAD delivery (non-PAD private hospitals). Public hospitals belong to the public healthcare system while private hospitals do not 11 We consider that a private hospital is a PAD private hospital if it had at least one delivery financed by PAD delivery in 2001-2005. In 2005, there were 233 hospitals with positive deliveries: $61 \mathrm{PAD}$ private hospitals, 9 non-PAD private hospitals, and 163 public hospitals.

Figure 4 characterizes hospitals in terms of their C-section rates and maternity specialization (measured by the ratio of deliveries over total hospitalizations) in 2002, prior to the policy change analyzed here. PAD private hospitals (diamonds) have high C-section rates to such extent that there is almost no overlap in terms of $\mathrm{C}$-section rates between these hospitals and public hospitals (circles) and non-PADprivate hospitals (triangles). Moreover, the PAD private hospitals with the higher C-section rates are highly specialized in maternity hospitalization. This evidence suggests that PAD private hospitals pursue a business model with specialization in deliveries financed by public insurance.

Table 2 shows summary statistics of hospital discharge data. The summary statistics show that $31 \%$ of all deliveries are C-sections, but the C-section rate is $58 \%$ in PAD private hospitals, $37 \%$ in non-PAD private hospitals and $25 \%$ in public hospitals. Of all deliveries, $17 \%$ occur at PAD private hospitals, $3 \%$ at non-PAD

\footnotetext{
${ }^{10}$ As we explain below, we restrict our sample to the period 2001-2005 to avoid contamination from confounding policies established subsequent to the policy of interest.

${ }^{11}$ It follows from the above definition that teaching hospitals and military hospitals are classified as private hospitals.
} 


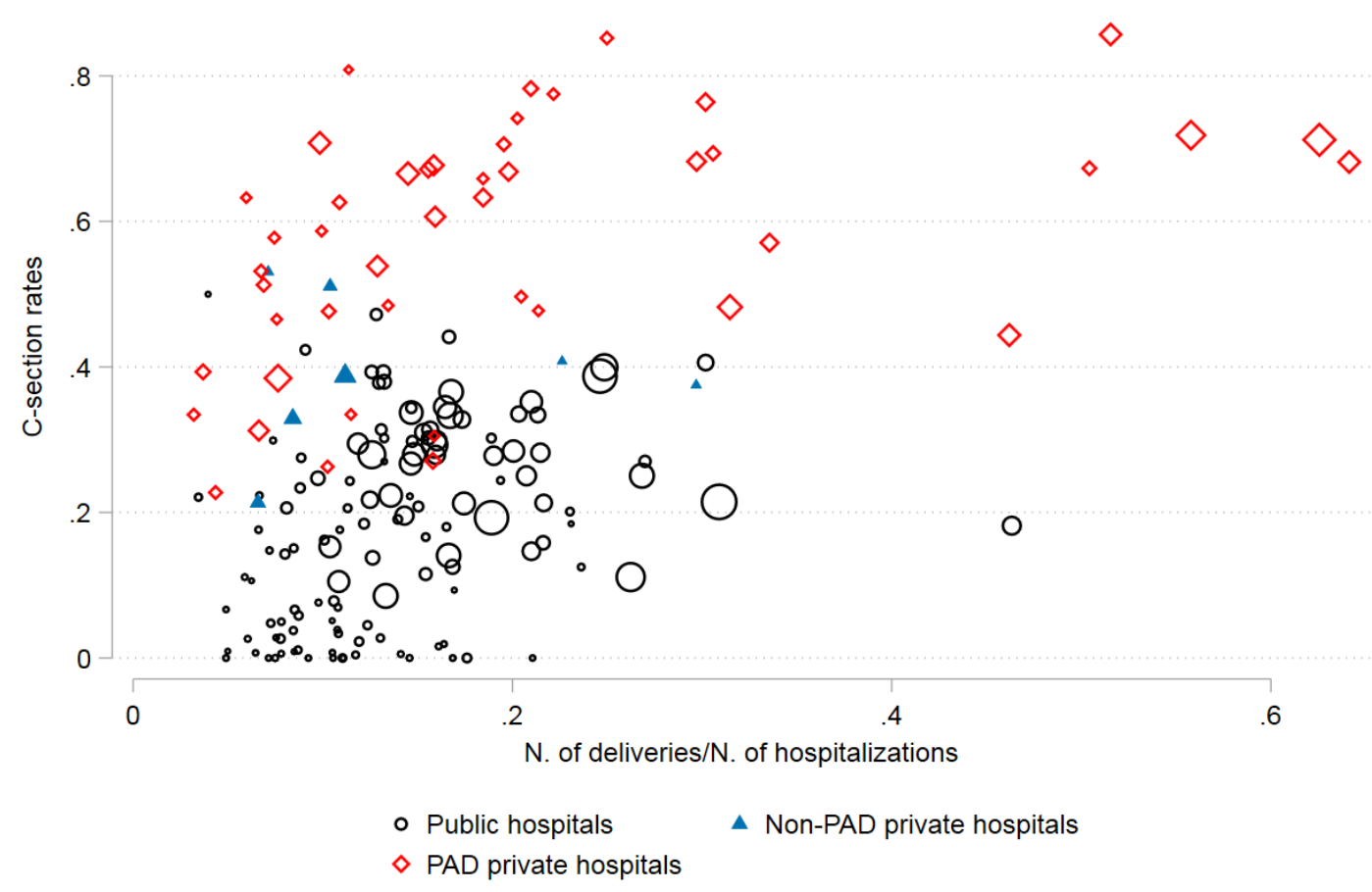

Sample: Hospitals with 100 or more deliveries in 2002.

Note: The size of the circle is proportional to the number of deliveries in the hospital in 2002.

Figure 4: Distribution of hospitals by C-section rates and maternity specialization, 2002

private hospitals and $80 \%$ at public hospitals. The distribution of deliveries by the mother's insurance affiliation is: $44 \%$ for public insurance A, $36 \%$ for public insurance B, C or D and $14 \%$ for private insurance. The average mother's age is 26.9 years.

Figures $5 \mathrm{a}$ and $5 \mathrm{~b}$ show the trends in deliveries at PAD private hospitals and in C-section rates for women with different types of insurance for 2001-2005. Figure 5b shows that for women in groups B, C or D, the share of deliveries at PAD hospitals went from $8 \%$ in 2002 to $27 \%$ in 2005, while remaining stable for the other groups. Figure $5 \mathrm{~b}$ shows that $\mathrm{C}$-section rates correlated closely with the type of insurance: $20-25 \%$ for women in group A, $35 \%$ for women in groups B, C and D, and $50 \%$ for women with private insurance. More relevant for our work, C-section rates increased after the policy change for eligible groups (groups B, C or D) but remained fairly 


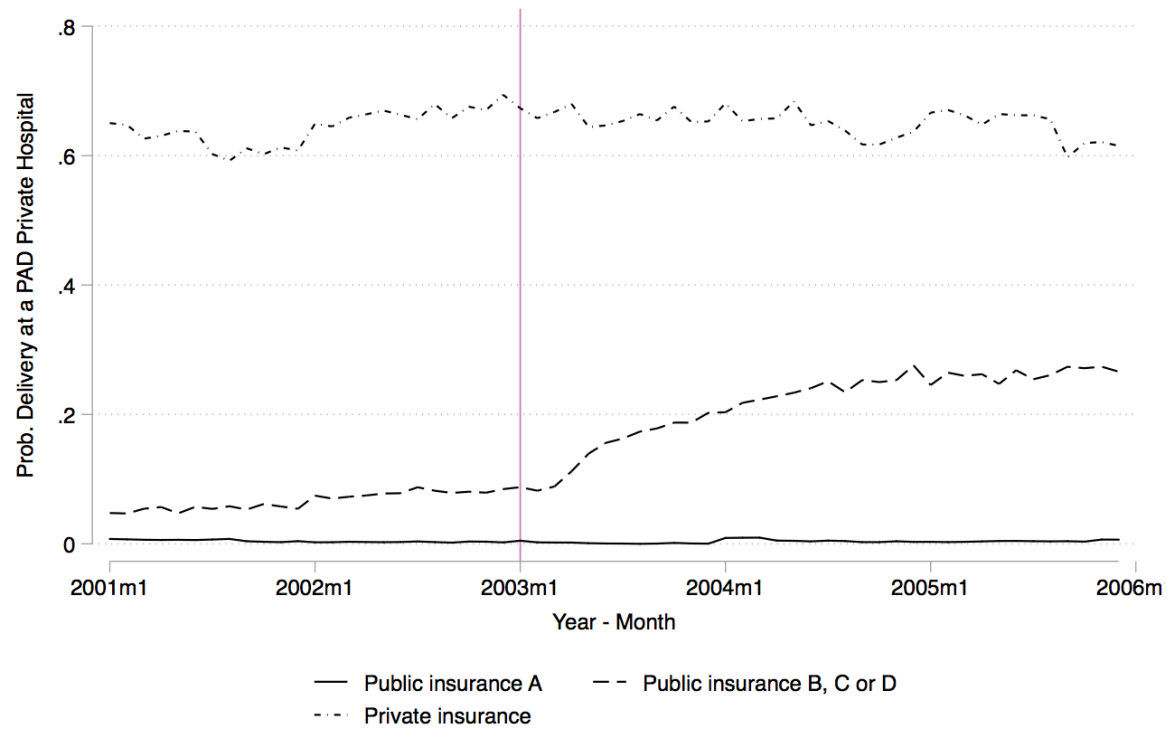

(a) Delivery at a PAD private hospital

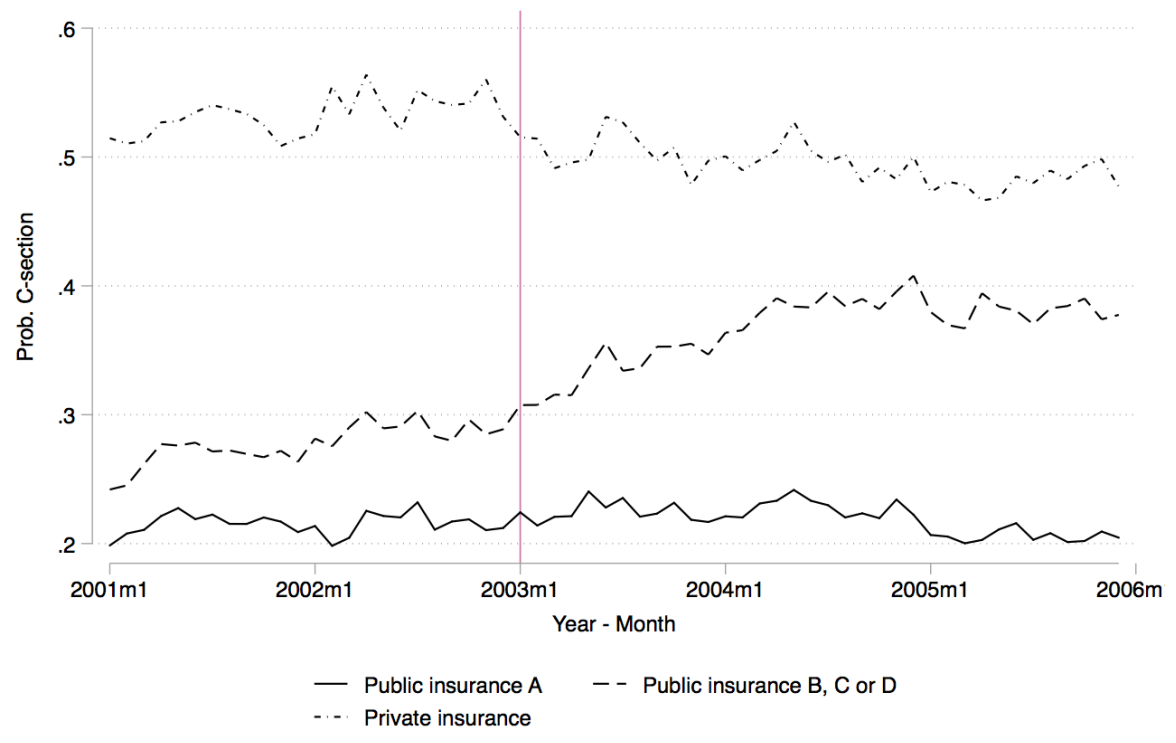

(b) C-section rates

Figure 5: Trends in delivery at PAD private hospitals and in C-section rates by the type of insurance 
constant for non-eligible groups (group A and private insurance). This gives a sense of the impact of the policy on C-section rates.

Our second source of data, which we use for the policy impact on newborn outcomes in Section 6 and to study the underlying mechanism of our results in Section 7 is DEIS birth data. After a birth, hospital staff completes a birth form that parents use to register and obtain a birth certificate for the newborn. DEIS collects these data for all births in Chile and the dataset is publicly available for the period 1996-2016. The data include information on the date of date, the mother's age, the baby's gestational age, weight and size at birth, whether it is a single or multiple birth, the person that delivers the baby (doctor, midwife or other), and the mother's data (county of residence, marital status, parity, educational level and labor force participation). We restrict our birth sample to mothers between 15 and 47 years of age that gave birth in a hospital at a gestational age between 30 and 42 weeks. For the analysis in Section 6, we restrict the sample to 1996-2005, and for Section 7, we restrict the sample to 2003-2016. ${ }^{12}$

Table 3 reports summary statistics for birth data. The main characteristics of births are: average birth weight is 3.4 kilograms, average size at birth is 49.5 centimeters and average gestational age at birth is 38.8 weeks. Moreover, 94 percent are single, term births, 6 percent are preterm births, and 2 percent are multiple births. The average age of mothers is 26.9 years, $51 \%$ are married, $27 \%$ are active in the labor market, and they have an average of 2 children at the time of delivery.

\section{Empirical Strategy}

In this section, we use hospital discharge data to measure the impact of the policy on the probability of a delivery occurring at a PAD private hospital and the probability of a C-section. To estimate this impact, we follow a DID strategy that exploits both the 2003 decrease in the copayment for PAD delivery and eligibility conditions to use PAD delivery. As noted in a previous section, the requirements for a PAD delivery were belonging to public insurance groups $\mathrm{B}, \mathrm{C}$, or $\mathrm{D}$, expecting a single

\footnotetext{
${ }^{12}$ We restrict our sample to the period 2003-2016 because the names of hospitals have only been reported in birth data since 2003.
} 
baby and having a pregnancy with a gestational age of 37 weeks or more. Given that hospital discharge data includes the type of insurance at the time of delivery and the single/multiple delivery condition, a "naive" approach would be to use the affiliation to groups B, C, or D and the single baby indicator as the treatment variables.13 However, one problem with this strategy is the possibility of women switching from private to public insurance because of the policy. Therefore, to approximate the mother's insurance affiliation before the policy change, we used the share of deliveries by women in groups B, C and D by county and age in 2002 as our treatment intensity variable.

Our estimating equation is

$Y_{i t}=\beta_{0}+\beta_{1}$ Share Group B, Cor D $D_{a c} \times$ Single $_{i t} \times$ Post $_{t}+\beta_{3} X_{i t}+\mu_{t}+\delta_{a c}+\lambda_{a y}+\epsilon_{i t}$

where $Y_{i t}$ is the outcome variable (a dummy for delivery at a PAD private hospital or a dummy for cesarean section delivery) for delivery $i$ in month-year $t$, Share Group B, Cor $D_{a c}$ is the share of deliveries in 2002 by women in public insurance B, C or D of age $a$ and living in county $c$, Single $e_{i t}$ is a dummy variable for single birth, Post $_{t}$ is a dummy that equals one after January 2003, and $X_{i t}$ includes Single $_{i t}$ and its interaction with Share Group B, Cor $D_{a c}$. Finally, $\mu_{t}$ is a month-year fixed effect, $\delta_{a c}$ is a mother's age-county of residence fixed effect, $\lambda_{a y}$ is a mother's age-year fixed effect, and $\epsilon_{i t}$ includes unobservables that affect the outcome variable. In our estimating equation, $\beta_{1}$ captures the causal effect of interest.

Our identification strategy relies on the following main assumptions: no compositional changes for groups subject to different program intensities, common trends without the policy for the different groups, and no contemporaneous confounding policy changes. We justify each assumption below.

First, treatment intensity depends on the mother's county of residence and age (used as predictors of insurance affiliation before the policy) and single/multiple birth status. The mother's county of residence and age are unlikely to change as a consequence of the policy because: (i) policy eligibility has no relationship to

\footnotetext{
${ }^{13}$ The results of the "naive" approach, which include the individual insurance type, are presented in the Appendix.
} 


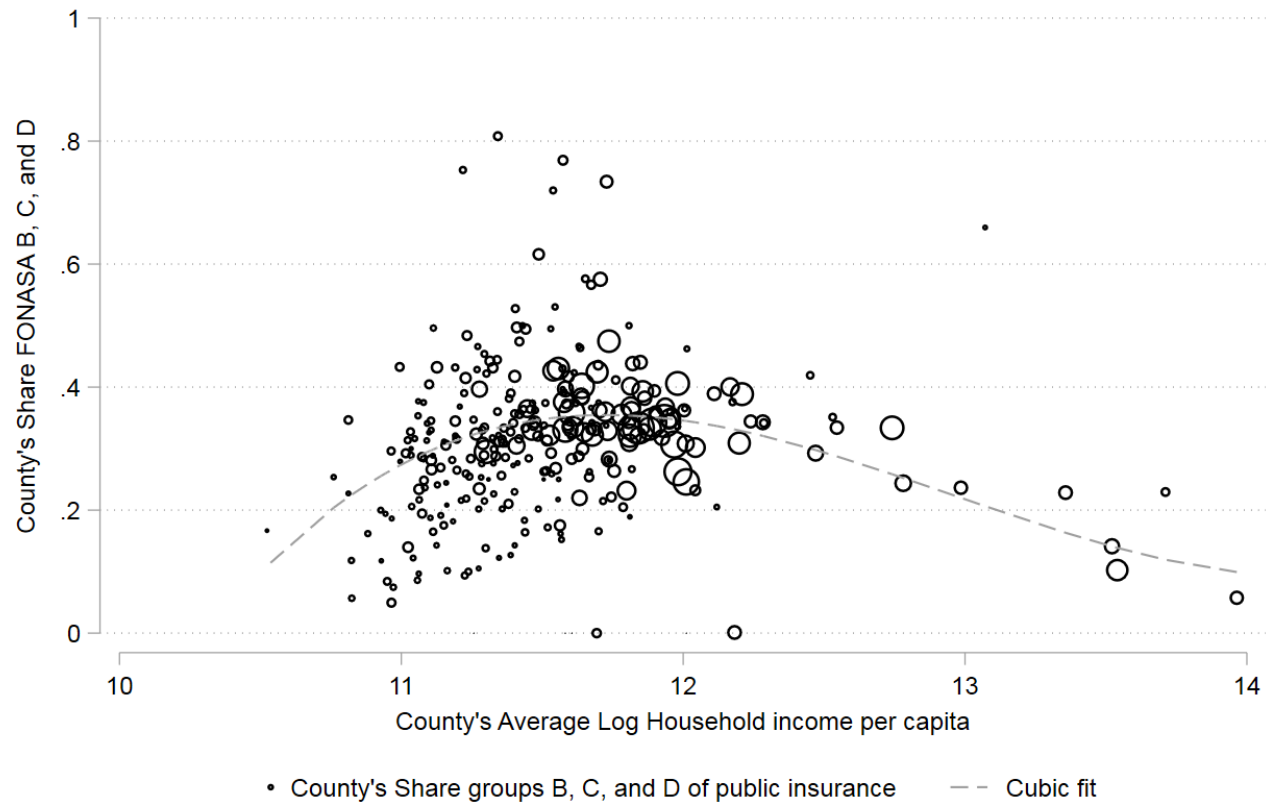

Figure 6: Average household income per capita and share of public insurance groups $\mathrm{B}, \mathrm{C}$ or D by county, 2002

these variables, and (ii) neither fertility nor birth timing is likely to be affected by a policy that increases options for delivery. Fortunately, these two variables are good predictors of being in groups $\mathrm{B}, \mathrm{C}$ or $\mathrm{D}$. In particular, county of residence is a good predictor of household income, which in turn is a good predictor of affiliation in groups $\mathrm{B}, \mathrm{C}$ or D. Figure 6 shows the relationship between household income and the share of deliveries by women in B, C and D at the county level. There is an inverse U-shaped relationship: in that the share of deliveries by women in groups B, $\mathrm{C}$ or $\mathrm{D}$ is higher in middle-income counties than in low- and high-income counties.

In the case of single/multiple birth status, whether or not a woman is expecting a single baby is unlikely to manipulate by women or doctors. That said, a concern is a trend among women to delay fertility decisions (through fertility methods), which could result in more multiple and premature births. To overcome this concern, we control for the mother's age-year fixed effect that explicitly captures this trend.

Second, we tested the presence of parallel trends in the pre-treatment period to 
justify the assumption of common trends for groups subject to different program intensities. With that purpose, we estimated the following econometric model:

$$
\begin{gathered}
Y_{i t}=\beta_{0}+\sum_{\tau=1}^{T} \beta_{\tau} \text { Share Group B, Cor D } D_{a c} \times \text { Single }_{i t} \times \mathbb{1}(t=\tau) \\
\beta_{3} X_{i t}+\mu_{t}+\delta_{a c}+\lambda_{a y}+\epsilon_{i t}
\end{gathered}
$$

where each $\beta_{\tau}$ is the coefficient of the interaction between a month-year dummy and the intensity of the program, taking December 2002 as the baseline. Figures $7 \mathrm{a}$ and $7 \mathrm{~b}$ show the results for the probability of delivery at a PAD private hospital and the probability of a C-section, respectively. Consistent with the common trend assumption, the coefficients fluctuate around zero before the policy change and become significantly positive afterward.

The final assumption behind our specification is that there are no contemporaneous confounding policy changes. We are particularly concerned with two policies: i) a change in the regulatory framework for private insurance companies that restricts their discretion to change premiums, and ii) a new policy called AUGE/GES that grants better coverage for individuals with certain health conditions, including preterm birth. Regarding the first policy, the change in the regulatory framework for private insurance companies was approved in May of 2005, but put into effect the following year. We restrict our sample to 2005 so it would not affect our results. Regarding the second policy, AUGE/GES was approved in 2004 but put into effect from July 2005 onwards. When we restrict our sample to June of 2005, the results do not change.

\section{Results and discussion}

Table 4 presents the estimates of equation (1) for the probability of delivery at a PAD private hospital (column (1)) and the probability of a C-section (column (2)). As we can observe, the policy change increased the probability of delivery at a PAD private hospital by 8.7 percentage points, and increased the probability of a C-section by 4.6 percentage points. In terms of the sample means of these variables, this implies that in the first three years after the policy was introduced, it increased 


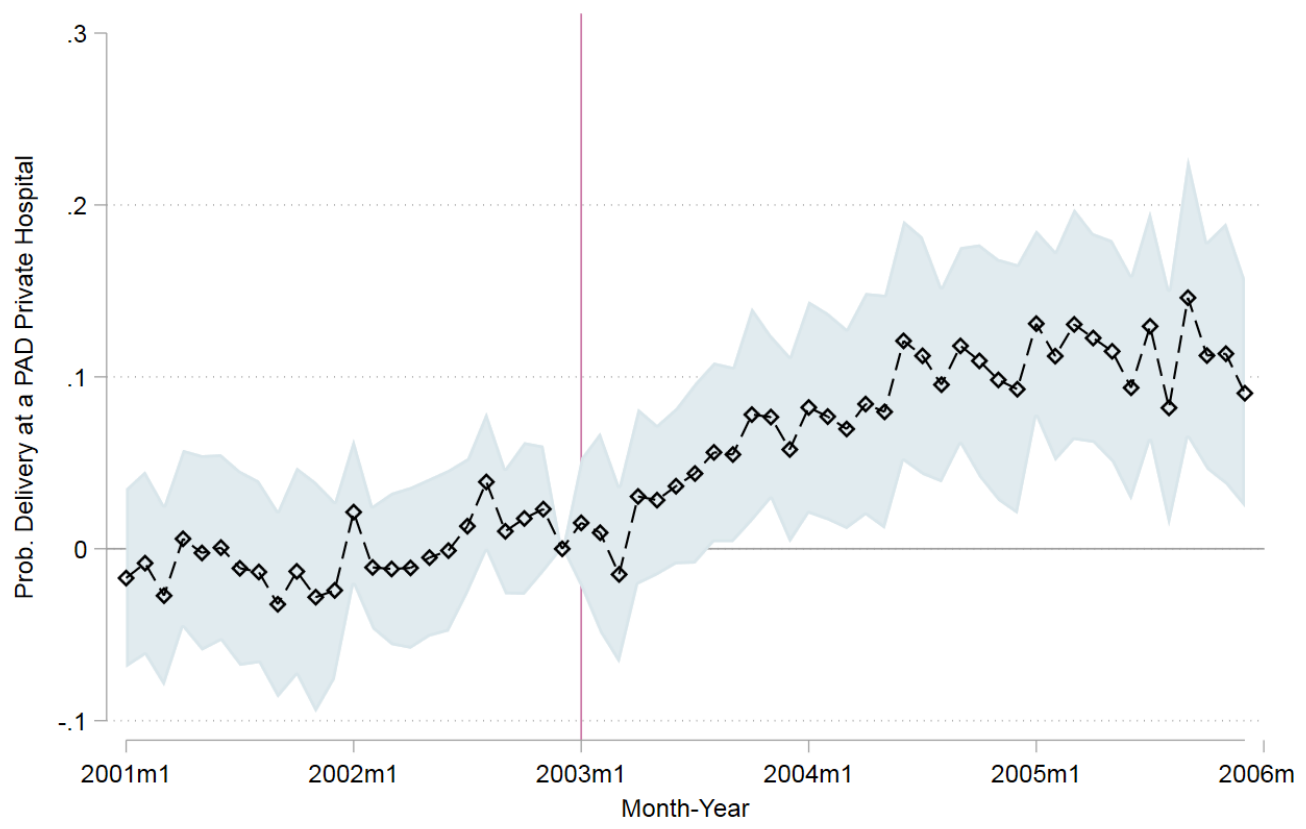

(a) Probability of a delivery at a PAD private hospital

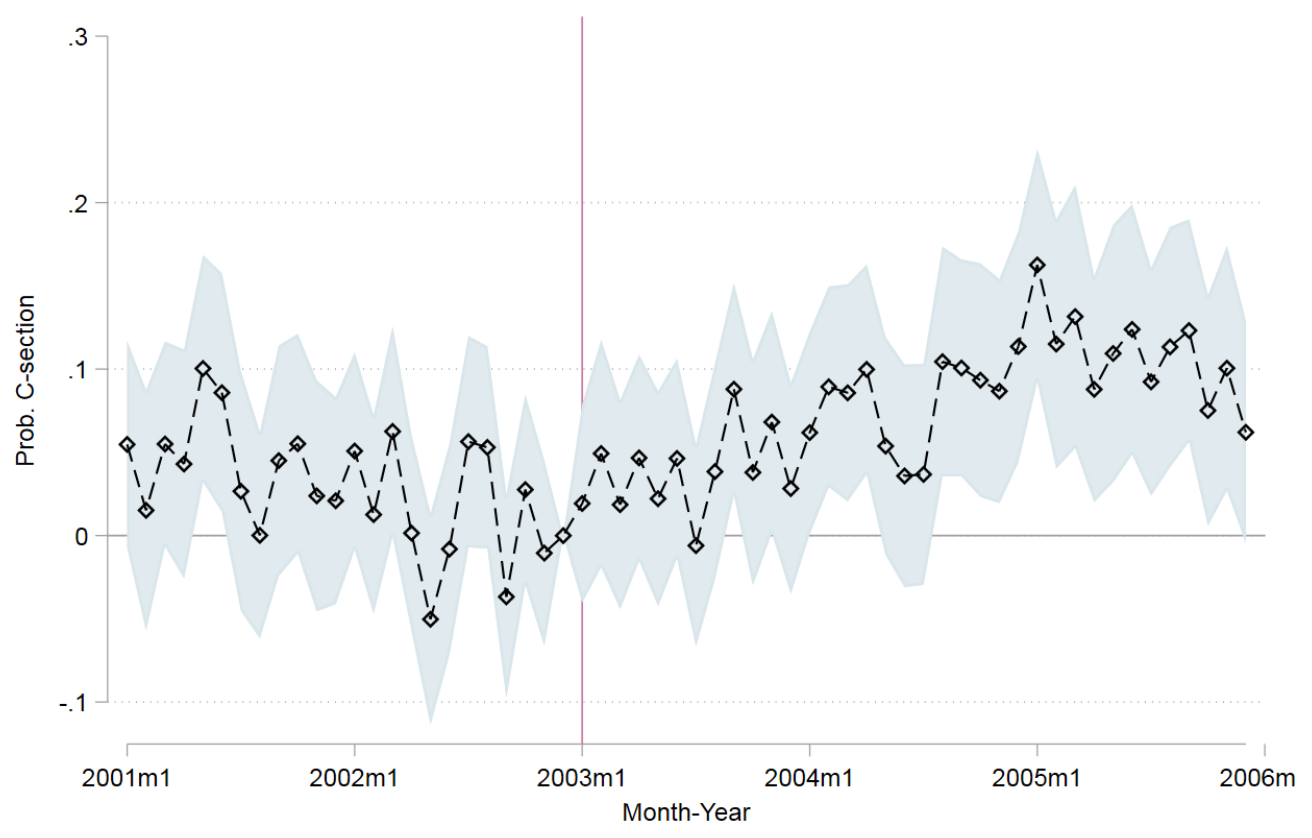

(b) Probability of a C-section delivery

Figure 7: Time-varying effects of the program 
private hospital deliveries by around $51 \%$ and the probability of a $\mathrm{C}$-section by around $15 \%$

The previous results can be interpreted either as a consequence of incentives to hospitals/physicians to perform C-sections or as an interaction of these incentives with patients' preferences. The latter implies that women with public health insurance have a marked preference for a C-section that is "satisfied" by private hospitals, but not by public hospitals. However, the available evidence does not seem to support this claim (for example, see McCourt et al., 2007). 15 Using a survey of pregnant women in Santiago, Chile, Angeja et al. (2006) found that $77.8 \%$ of respondents preferred vaginal delivery and only $9.4 \%$ preferred C-section delivery. The results are similar for women interviewed in public hospitals (C-section rate of $22 \%$ ) and in private hospitals (C-section rate of $60 \%){ }^{16}$

In Section 7 we provide evidence in support of hospital/physician incentives to use C-sections to smooth out demand over time to optimize the use of hospital resources.

\section{An IV interpretation}

We can use our empirical strategy to estimate the impact of being attended in a PAD private hospital on the probability of a C-section in the context of the policy. To do this, we instrument the decision to give birth in a PAD private hospital with the policy change to estimate the impact on the probability of a C-section. However, we should interpret this impact with caution because we are analyzing the effect of being attended in a PAD private hospital when the hospital demand has increased considerably (as a consequence of the policy). Therefore, our IV results may indicate

\footnotetext{
${ }^{14}$ These results are around half of those obtained with the "naive" strategy of directly using current insurance affiliation in the treatment variables (see the Appendix for details). This suggests some degree of strategic switching from private to public insurance by women who had C-section delivery at a PAD private hospital.

15 McCourt et al. (2007) reviewed the research literature on consumer preferences for elective cesarean section since 2000 , and found that very small numbers of women request a C-section, ranging from 0.3 to $14 \%$.

${ }^{16}$ Another factor that might affect the increasing number of C-sections is procedural skill (see Currie and MacLeod, 2016). It may be that physicians at private hospitals are more likely to be surgically skilled than those at public hospitals. However, we still need an explanation for private hospitals being more prone to hiring more surgically skilled doctors.
} 
both the effect of giving birth in a PAD private hospital and the reaction of hospitals to the rapid increase in demand (a congestion effect) on C-section probability.

Table 5 presents the OLS (column (1)) and IV (column (2)) estimates for the impact of delivery at a PAD private hospital on C-sections. We find that the IV estimates (of around 54 percentage points) are higher than the OLS estimates (around 31 percentage points). A plausible explanation for the downward bias in the OLS estimates derives from interpreting the IV estimates as LATE on compliers. In order to interpret the magnitude of our estimates, it is important to characterize who the compliers to this policy are: middle-income women that have public insurance and enough income to pay the copayment. Assuming that the OLS estimates an average treatment effect on the treated (ATT), it would measure the effect of a delivery at a private hospital for middle and high-income women. If middle-income women are less informed than high-income women, we could expect a larger effect on this subpopulation, which is exactly the complier population in the IV framework ${ }^{17}$

We show evidence consistent with this interpretation in Figure 8 . Note that the rate of $\mathrm{C}$-sections has an inverted-U shape with the share of deliveries with private insurance (which can be seen as a proxy for the average income of patients). That is, C-section rates are higher in hospitals focused on middle-income women than in hospitals focused on high- or low-income women (public hospitals).

A different interpretation is that the group of compliers includes a selection of riskier patients, i.e. women with an ex-ante greater likelihood to have C-section delivery. However, as noted in Section 2, one of the conditions to receive PAD is that the pregnancy is not high-risk, and the chosen private hospital has the right to determine this condition. Hence, hospitals are unlikely to accept high-risk pregnancies under the PAD system.

\footnotetext{
${ }^{17}$ This argument is consistent with the results in Johnson and Rehavi (2016), who found that, while C-section rates for non-physician patients (uninformed patients) are lower in HMO-owned hospitals than in non-HMO-owned hospitals, C-section rates for physician patients (informed patients) do not depend on hospital ownership.
} 


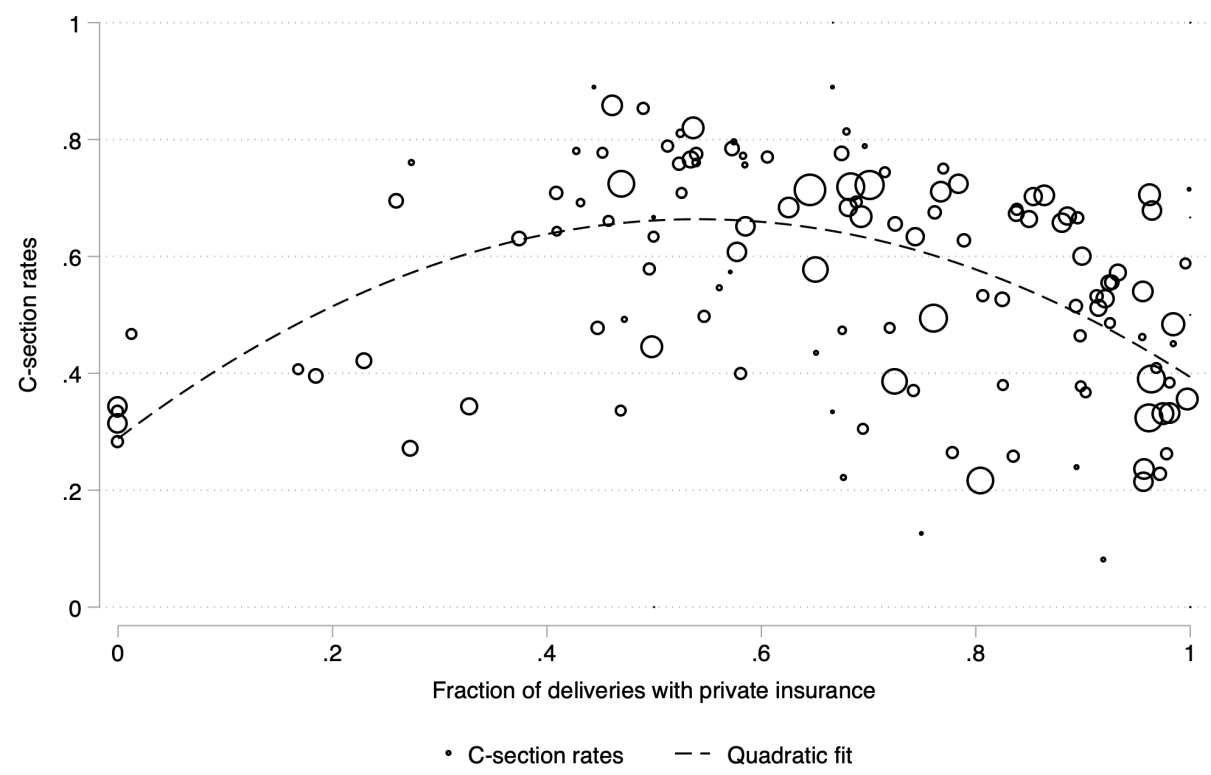

Figure 8: Fraction of patients with private insurance and C-section rate by hospital, 2001-2002

\section{Impact of the policy on newborn outcomes}

In this section, we use birth data to evaluate the impact of the policy on two newborn outcomes: weight and size at birth. To estimate this impact, we follow a similar procedure to that in Section 4. Because birth data contains information on gestational age, we consider an additional eligibility condition: a birth with a gestational age of 37 weeks or more. The use of birth data allows us to test the assumption of parallel trends for a longer period of time since we use data back to 1996.

Our estimating equation is

$$
\begin{gathered}
Y_{i t}=\beta_{0}+\beta_{1} \text { Share Group B, Cor D } D_{a c} \times \text { Single }_{i t} \times \text { Term }_{i t} \times \text { Post }_{t} \\
+\beta_{2} X_{i t}+\mu_{t}+\delta_{a c}+\lambda_{a y}+\epsilon_{i t},
\end{gathered}
$$

where $Y_{i t}$ is the outcome variable (weight or size at birth) of newborn $i$, born in month-year $t$, Share Group B, C or $D_{a c}$ is the share of deliveries in 2002 by women in 
public insurance group B, C or D, of age $a$ and living in county $c$, Single $_{i t}$ is a dummy variable for single birth, Term $_{i t}$ is a dummy for term birth, Post $t_{t}$ is a dummy that equals one after January 2003. In this case, X includes $X_{i t}$ includes Single $i t, T e r m_{i t}$, Single $_{i t} \times$ Term $_{i t}$ and their interactions with Share Group B,Cor $D_{a c}$, as well as the mother's characteristics (parity, educational level and labor force participation), and $\epsilon_{i t}$ includes unobservables that affect the outcome variable.

Table 6 reports the effects of the policy on birth weight (columns (1) and (2)) and size at birth (columns (3) and (4)). We find that the policy change causes a decrease of 19-21 grams in weight and of 0.09 centimeters in size at birth.

We use the pre-treatment period to evaluate the main identifying assumption about common trends for groups subject to different program intensity. To do that, we estimate the following econometric model:

$$
\begin{gathered}
Y_{i t}=\beta_{0}+\sum_{\tau=1996}^{2005} \beta_{\tau} \text { Share Group B, Cor D } D_{a c} \times \text { Single }_{i t} \times \text { Term }_{i t} \times \mathbb{1}(y=\tau) \\
\beta_{3} X_{i t}+\mu_{t}+\delta_{a c}+\lambda_{a y}+\epsilon_{i t},
\end{gathered}
$$

As above, every $\beta_{\tau}$ here is the coefficient of the interaction between a year dummy and the intensity of the program, taking 2002 as the baseline year.

Figures $9 \mathrm{a}$ and $9 \mathrm{~b}$ show the results for birth weight and size at birth, respectively. Only the coefficient in 1996 is statistically significant at 5\%, and there is a clear negative effect after the policy change.

\section{Expected demand for deliveries and hospital schedul- ing decisions}

We have shown that a policy that decreased the cost of delivery at private hospitals had a notable impact on C-section rates in Chile. In this section, we propose and find evidence of a mechanism that explains this result. As stated in Section 11, the PAD program pays private hospitals the same price for a vaginal or cesarean delivery, 


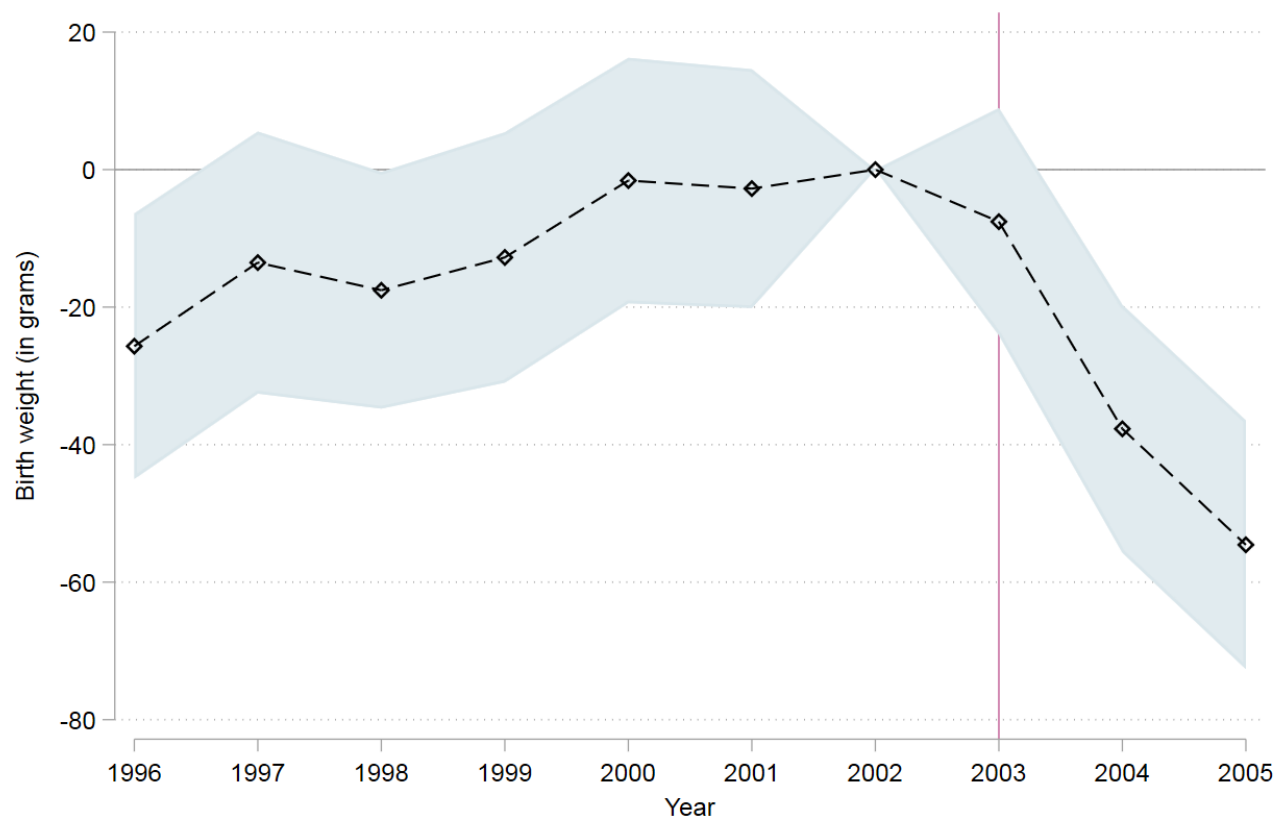

(a) Average birth weight

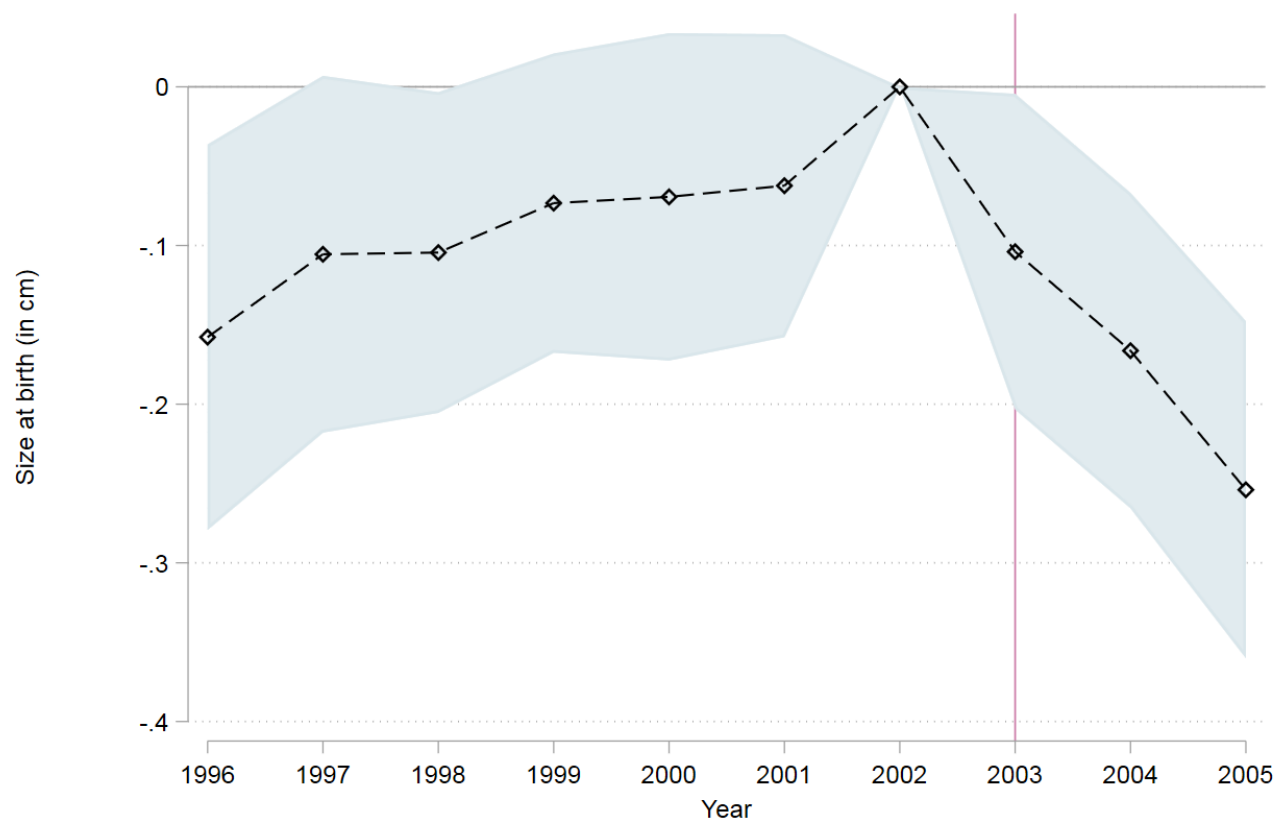

(b) Average size at birth

Figure 9: Impact of the policy on newborn outcomes 
the latter being costlier ${ }^{18}$ In the absence of price incentives, hospitals may profit from increased demand due to the policy by accommodating the maximum number possible of deliveries in a period of time. Because C-sections can be scheduled, they provide the hospital more flexibility to accommodate deliveries in a way that optimizes the use of their resources. Therefore, our hypothesis is that a high Csection rate allows hospitals to smooth out demand over time by moving deliveries between high and low demand weeks. 19

To test if hospitals manipulate the date of birth as a function of their demand, we need a measure of expected hospital demand that is not subject to that kind of manipulation. Since birth data contains gestational age, we measure expected hospital demand in a week by adding all births in a week for all hospitals, assuming full-term delivery (at a gestational age of 40 weeks), regardless of the actual date of birth. Then, to identify high and low expected demand weeks, we use the 25th, 50 th and 75 th percentiles of the distribution of expected demand for a hospital in a given year.

Given our definition of high and low expected demand weeks, we want to know whether the actual date of birth of a baby born in a given hospital is a function of that demand. Specifically, we want to know if the probability of an early term birth (on week 37 or 38) depends on the expected demand that the hospital may face during week 40 of that pregnancy. To do that, we use birth data for the period 2003-2016 to estimate the following equation: ${ }^{20}$

\footnotetext{
${ }^{18}$ We can approximate the differences in costs for a C-section and a vaginal delivery using claims data from private insurance that use fee-for-service payment schemes. Based on the data, private hospitals receive between 11 and $28 \%$ more from private insurance companies for a C-section than a vaginal delivery.

${ }^{19}$ Our question is related to recent papers on the effect of hospital congestion on C-sections. For example, using data from a large public hospital in Italy and (unlike our case) leaving out all scheduled deliveries, Facchini (2016) found that C-sections are more likely when there is a high patient/midwife ratio. Using data on maternity admissions for 30 hospitals in Washington state, Balakrishnan and Soderstrom (2000) only found a correlation between C-sections and "congested" days for pregnancies that were classified as at risk for C-section, but not for the full sample of patients. These works differ crucially from ours in that they investigate whether hospitals are more likely to perform C-sections when faced with unexpected demand, while we are concerned with hospitals systematically using C-sections to program their deliveries to accommodate demand.

${ }^{20}$ Our sample starts in 2003 because the name of the hospital where a woman gives birth has only been reported in birth data since that year.
} 


$$
\begin{aligned}
Y_{i w y}= & \beta_{0}+\beta_{1} \text { demand_25_50_pct } l_{h w y}+\beta_{2} \text { demand_50_ }_{-} \text {75_pct } l_{h w y} \\
& +\beta_{3} \text { demand_75_more }_{h w y}+\beta_{4} X_{i w y}+\mu_{w}+\delta_{h y}+\lambda_{a y}+\epsilon_{i w y}
\end{aligned}
$$

where $Y_{i w y}$ is a dummy for early term birth (on week 37 or 38) for birth $i$, the fullterm delivery date which (week 40 of pregnancy) occurs in week $w$ of year y. Here, demand_25_50_pctl, demand_50_75_pctl and demand_75_more are dummies indicating the percentile of expected demand (between the 25th and 50th percentile, between the 50 th and 75 th percentile, or above the 75 th percentile, respectively) in week $w$ for hospital $h$ in yeary, and $X_{i w y}$ includes a single birth dummy, a term birth dummy, and the mother's characteristics (parity, educational level and labor force participation), while $\mu_{w}$ is a week fixed effect, $\delta_{h y}$ is a hospital-year interaction, and $\lambda_{a y}$ is a mother's age-year interaction. ${ }^{21}$

The $\beta$ 's in equation (5) measure the effect on the probability of an early term birth of expected demand a hospital faces in the week the pregnancy reaches week 40. By using the week of full-term delivery, our source of variation here is the week of conception. Identification also relies on hospital-year interactions that capture unobserved differences between hospitals potentially correlated with C-section probability, like management quality, composition of the medical staff, hospital infrastructure and hospital demand composition. These unobservables are allowed to vary over time.

Table 7 shows the effects of expected demand on the probability of an early term birth for public and non-PAD private hospitals (column (1)), and for PAD private hospitals (column (2)). The impact of high expected demand on early term birth for public and non-PAD private hospitals is close to zero, but this is not the case for PAD private hospitals. Specifically, we find that if a pregnancy reaches week 40 on an expected higher than normal demand week, the probability of an early term birth increases by $0.4 / 0.6$ percentage points. In terms of the sample mean, this is

\footnotetext{
${ }^{21}$ The results in this Section are robust to an alternative specification that uses the ratio between expected demand and the maximum number of (actual) weekly deliveries in the year (as a measure of hospital capacity) instead of the distribution of expected demand. The results for this alternative specification are shown in the Appendix.
} 
around a $1.1 / 1.6 \%$ increase given that $36 \%$ of births in our sample occur on week 37 or 38 . Therefore, our results point to private hospitals scheduling deliveries as a function of their expected demand.

In Table 8, we allow for heterogeneity in the impact of expected demand on PAD private hospitals, by classifying them in terciles by their average fraction of C-sections for 2003-2016. ${ }^{22}$ Note that, as in the case of public and non-PAD private hospitals, we did not find an effect of high expected demand on PAD private hospitals with low C-section rates (25-65\%) (column (1)). Therefore, the impact of expected demand appears to be concentrated in hospitals where C-sections represent more than $65 \%$ of deliveries, being higher for those hospitals with high C-section rates (over 77\%) (column (3)). As well, note that the effect increases with expected demand, as shown in columns (2) and (3).

Two interpretations of these results are possible: (i) hospitals/physicians indicate more C-sections when faced with high expected demand, or (ii) high C-section rates allow hospitals/physicians to move deliveries from weeks with high expected demand to weeks with low expected demand. We believe the second interpretation makes more sense, and the fact that this effect is only present in PAD hospitals with high C-section rates is consistent with this interpretation.

\section{Conclusion}

We study the effect on cesarean rates of a policy in Chile that decreased the cost of delivery at private hospitals for women with public health insurance. Our identification strategy relies on the eligibility conditions to access this benefit: women with public insurance expecting a single baby with a gestational age of 37 weeks or more, with the exception of women with no income. Using hospital discharge data, we use a difference-in-differences (DID) estimation strategy to measure the impact of the policy on the probability of delivery at a private hospital and on the probability of having a C-section. In the first three years since the introduction of the policy, private hospital deliveries increased by 8.7 percentage points ( $51 \%$ increase in terms

\footnotetext{
${ }^{22}$ The $\mathrm{C}$-section rate is between 25 and $65 \%$ in low C-section rate PAD hospitals, between 65 and $77 \%$ in intermediate C-section rate hospitals, and over $77 \%$ in high C-section rate hospitals.
} 
of the sample mean) and the probability of a C-section increased by 4.6 percentage points (15\% increase). Applying a similar strategy to birth data, we find the policy had a negative effect on newborn weight and size.

Given that the policy studied here implies a flat price for delivery, independent of the procedure, it is unlikely that price incentives are the main channel behind the aforementioned results. Therefore, using birth data, we studied the possibility that private hospitals indicate C-sections to smooth out demand over time to optimize the use of their resources. We find a higher probability of early term birth when a private hospital participating in the program has higher than normally expected demand for deliveries, and no effect for non-participating hospitals. 


\section{References}

Alexander, J. M., K. J. Leveno, J. Hauth, M. B. Landon, E. Thom, C. Y. Spong, M. W. Varner, A. H. Moawad, S. N. Caritis, M. Harper, R. J. Wapner, Y. Sorokin, M. Miodovnik, M. J. O’Sullivan, B. M. Sibai, O. Langer, and S. G. Gabbe (2006). Fetal injury associated with cesarean delivery. Obstetrics $\&$ Gynecology 108(4), 885-890.

Allin, S., M. Baker, M. Isabelle, and M. Stabile (2015). Physician incentives and the rise in C-sections: Evidence from Canada. Working Paper 21022, National Bureau of Economic Research.

Ananth, C. V., J. C. Smulian, and A. M. Vintzileos (1997). The association of placenta previa with history of cesarean delivery and abortion: A metaanalysis. American Journal of Obstetrics and Gynecology 177(5), 1071-1078.

Angeja, A., A. Washington, J. Vargas, R. Gomez, I. Rojas, and A. Caughey (2006, 2018/12/17). Chilean women's preferences regarding mode of delivery: which do they prefer and why? BJOG: An International Journal of Obstetrics \& Gynaecology 113(11), 1253-1258.

Balakrishnan, R. and N. S. Soderstrom (2000, 09). The cost of system congestion: Evidence from the healthcare sector. Journal of Management Accounting Research 12, 97-114.

Betrán, A. P., J. Ye, A.-B. Moller, J. Zhang, A. M. Gülmezoglu, and M. R. Torloni (2016, 02). The increasing trend in caesarean section rates: Global, regional and national estimates: 1990-2014. PLOS ONE 11(2), 1-12.

Borrescio-Higa, F. and N. Valdés (2018). Publicly insured caesarean sections in private hospitals: a repeated cross-section analysis in chile. Working paper, Universidad Adolfo Ibañez.

Card, D., A. Fenizia, and D. Silver (2018). The health effects of cesarean delivery for low-risk first births. Working paper. 
Costa-Ramón, A. M., A. Rodríguez-González, M. Serra-Burriel, and C. CampilloArtero (2018). It's about time: Cesarean sections and neonatal health. Journal of Health Economics 59, 46 - 59.

Currie, J. and W. B. MacLeod (2016). Diagnosing expertise: Human capital, decision making, and performance among physicians. Journal of Labor Economics 35(1), 1-43.

Facchini, G. (2016). Low staffing levels in maternity wards: Keep calm and call the surgeon. Working paper, European University Institute.

Foo, P. K., R. S. Lee, and K. Fong (2017). Physician prices, hospital prices, and treatment choice in labor and delivery. American Journal of Health Economics 3(3), 422-453.

Gruber, J., J. Kim, and D. Mayzlin (1999). Physician fees and procedure intensity: the case of cesarean delivery. Journal of Health Economics 18(4), 473-490.

Gruber, J. and M. Owings (1996). Physician financial incentives and cesarean section delivery. The RAND Journal of Economics 27(1), 99-123.

Hoxha, I., L. Syrogiannouli, X. Luta, K. Tal, D. C. Goodman, B. R. da Costa, and P. Jüni (2017). Caesarean sections and for-profit status of hospitals: systematic review and meta-analysis. BMJ Open $7(2)$.

Hyde, M. J., A. Mostyn, N. Modi, and P. R. Kemp (2012). The health implications of birth by caesarean section. Biological Reviews 87(1), 229-243.

Johnson, E. M. and M. M. Rehavi (2016). Physicians treating physicians: Information and incentives in childbirth. American Economic Journal: Economic Policy 8(1), 115-41.

Lien, H.-M., S.-Y. Chou, and J.-T. Liu (2008). Hospital ownership and performance: Evidence from stroke and cardiac treatment in taiwan. Journal of Health Economics 27(5), 1208 - 1223. 
McCourt, C., J. Weaver, H. Statham, S. Beake, J. Gamble, and D. K. Creedy (2007). Elective cesarean section and decision making: A critical review of the literature. Birth 34(1), 65-79.

Murray, S. F. (2000). Relation between private health insurance and high rates of caesarean section in chile: qualitative and quantitative study. BMJ 321(7275), $1501-1505$.

Murray, S. F. and M. A. Elston (2005). The promotion of private health insurance and its implications for the social organisation of healthcare: a case study of private sector obstetric practice in chile. Sociology of Health and Illness 27(6), $701-721$.

Shen, Y.-C. (2002). The effect of hospital ownership choice on patient outcomes after treatment for acute myocardial infarction. Journal of Health Economics 21(5), $901-922$.

Villar, J., G. Carroli, N. Zavaleta, A. Donner, D. Wojdyla, A. Faundes, A. Velazco, V. Bataglia, A. Langer, A. Narváez, E. Valladares, A. Shah, L. Campodónico, M. Romero, S. Reynoso, K. S. de Pádua, D. Giordano, M. Kublickas, and A. Acosta (2007). Maternal and neonatal individual risks and benefits associated with caesarean delivery: Multicentre prospective study. BMJ 335(7628), 1025 . 
Table 1: Construction of vaginal and cesarean delivery variables

\begin{tabular}{lccc}
\hline ICD-10 & Has surgery? & Vaginal delivery & Cesarean delivery \\
\hline O42, O601, O602, O603, O61- & & & \\
069, O71, O72, O74, O750, & No & $\mathrm{X}$ & \\
O751, O752, O753, O754, O755, & & & \\
O756, O758, O759, O848, O849 & & $\mathrm{X}$ \\
\hline $\begin{array}{l}\text { O42, O601, O602, O603, O61- } \\
\text { 069, O71, O72, O74, O750, }\end{array}$ & Yes & \\
O751, O752, O753, O754, O755, & & $\mathrm{X}$ & \\
O756, O758, O759, O848, O849 & & & \\
\hline O70, O73, O757, O80, O81, O83, & & & \\
O840, O841 & & \\
\hline O82, O842 & & \\
\hline
\end{tabular}


Table 2: Descriptive statistics for hospital discharge data, 2001-2005

\begin{tabular}{lcc}
\hline Variables & Mean & s.d. \\
\hline Cesarean section rate & 0.31 & 0.46 \\
$\quad$ in PAD private hospitals & 0.58 & 0.49 \\
$\quad$ in non-PAD private hospitals & 0.37 & 0.48 \\
$\quad$ in public hospitals & 0.25 & 0.43 \\
Delivery at a PAD private hospital & 0.17 & 0.38 \\
Delivery at a non-PAD private hospital & 0.03 & 0.18 \\
Delivery at a public hospital & 0.79 & 0.40 \\
Public insurance: Group A & 0.44 & 0.50 \\
Public insurance: Group B, C or D & 0.36 & 0.48 \\
Private insurance & 0.14 & 0.35 \\
Other insurance & 0.03 & 0.17 \\
Uninsured & 0.02 & 0.13 \\
Age & 26.9 & 6.7 \\
Patient's length of stay & 3.4 & 2.0 \\
\hline
\end{tabular}

Source: Departamento de Estadísticas e Información de Salud (DEIS), Ministerio de Salud, Chile. 
Table 3: Descriptive statistics for birth data, 19962005

\begin{tabular}{lcc}
\hline Variables & Mean & s.d. \\
\hline Birth weight & 3,356 & 514 \\
Size at birth & 49.5 & 2.4 \\
Single, term birth & 0.94 & 0.24 \\
Preterm & 0.06 & 0.23 \\
Multiple births & 0.02 & 0.13 \\
Gestational age at birth (in weeks) & 38.8 & 1.5 \\
Mother's age & 26.9 & 6.6 \\
Mother is married & 0.51 & 0.50 \\
Mother's labor force participation & 0.27 & 0.45 \\
Parity & 2.0 & 1.1 \\
\hline
\end{tabular}

Source: Departamento de Estadísticas e Información de Salud (DEIS), Ministerio de Salud, Chile. 
Table 4: Effect of easing access to private hospitals on the probability of delivery at a private hospital and the probability of a C-section delivery

Delivery at a PAD private hospital Cesarean section

(1)

\begin{tabular}{lcc}
\hline Share Public Insurance's B, C or D & $0.087^{* * *}$ & $0.046^{* * *}$ \\
$\quad \times$ Single $\times$ Post & {$[0.024]$} & {$[0.017]$} \\
\hline R-squared & 0.165 & 0.087 \\
Observations & 946,242 & 946,242 \\
\hline
\end{tabular}

Note: This table reports DID estimates of the effect of easing access to private hospitals on the probability of delivery at a private hospital and the probability of a C-section delivery. PAD private hospitals are hospitals that participate in the PAD program but are not in the public healthcare system. Share Public Insurance's B, C or D share of deliveries in 2002 by women in public insurance B, C or D of age $a$ and living in county $c$, Single is a dummy for single birth, and Post is a dummy that equals one after January 2003.

All regressions include Single, Single $\times$ Share Public Insurance's B, C or D, month-year fixed effects, mother's age-year of admission fixed effects, and mother's age-county of residence fixed effects.

Standard errors, clustered by mother's county of residence, reported in brackets.

*** Significant at the 1 percent level.

** Significant at the 5 percent level.

* Significant at the 10 percent level. 
Table 5: IV/2SLS estimates of the effect of delivery at a PAD private hospital on the probability of a C-section delivery

\begin{tabular}{|c|c|}
\hline & $\begin{array}{cc}\text { OLS } & \text { IV } / 2 \text { SLS } \\
(1) & (2)\end{array}$ \\
\hline Delivery at a PAD private hospital & $\begin{array}{ll}0.312^{* * *} & 0.537^{* * *} \\
{[0.015]} & {[0.200]}\end{array}$ \\
\hline Observations & 946,242 \\
\hline $\begin{array}{l}\text { Note: This table reports IV estimat } \\
\text { delivery at a PAD private hospital } \\
\text { a C-section delivery. PAD private } \\
\text { hospitals that participate in the PA } \\
\text { not in the public healthcare system. } \\
\text { Share Public Insurance's B, C or D } \\
\text { where Share Public Insurance's B, } \\
\text { of deliveries in } 2002 \text { by women in p } \\
\text { or D of age } a \text { and living in county } \\
\text { for single birth, and Post is a dumn } \\
\text { after January } 2003 \text {. } \\
\text { All regressions include Single, Sing } \\
\text { Insurance's B, C or D, month-year } \\
\text { mother's age-year of admission fixed } \\
\text { mother's age-county of residence fix } \\
\text { Standard errors, clustered by mothe } \\
\text { residence, reported in brackets. } \\
{ }^{* * *} \text { Significant at the } 1 \text { percent level } \\
{ }^{* *} \text { Significant at the } 5 \text { percent level. } \\
{ }^{*} \text { Significant at the } 10 \text { percent level. }\end{array}$ & $\begin{array}{l}\text { s of the effect of } \\
\text { the probability of } \\
\text { spitals are } \\
\text { program but are } \\
\text { The instrument is } \\
\times \text { Single } \times \text { Post } \\
\text { or D is the share } \\
\text { blic insurance B, C } \\
\text { Single is a dummy } \\
\text { y that equals one } \\
\text { ex Share Public } \\
\text { ixed effects, } \\
\text { effects, and } \\
\text { d effects. } \\
\text { 's county of }\end{array}$ \\
\hline
\end{tabular}


Table 6: Effect of easing access to private hospitals on newborn outcomes

\begin{tabular}{|c|c|c|c|c|}
\hline & \multicolumn{2}{|c|}{ Birth weight } & \multicolumn{2}{|c|}{ Size at birth } \\
\hline & (1) & (2) & (3) & $(4)$ \\
\hline $\begin{array}{l}\text { Share Public Insurance's B, C or D } \\
\quad \times \text { Single, term birth } \times \text { Post }\end{array}$ & $\begin{array}{c}-18.7^{* * *} \\
{[6.7]}\end{array}$ & $\begin{array}{c}-21.0^{* * *} \\
{[6.3]}\end{array}$ & $\begin{array}{c}-0.09^{* *} \\
{[0.04]}\end{array}$ & $\begin{array}{c}-0.09^{* *} \\
{[0.04]}\end{array}$ \\
\hline Additional Controls & No & Yes & No & Yes \\
\hline $\mathrm{R}$-squared & 0.234 & 0.241 & 0.235 & 0.237 \\
\hline Observations & $2,379,060$ & $2,379,060$ & $2,379,060$ & $2,379,060$ \\
\hline
\end{tabular}

Note: This table reports DID estimates of easing access to private hospitals on newborn outcomes. Share Public Insurance's B, $C$ or $D$ is the share of deliveries in 2002 by women in public insurance B, C or D of age $a$ and living in county $c$, Single, term birth is a dummy for a single, term birth, and Post is a dummy that equals one after January 2003. The controls include parity, mother's educational level and labor force participation.

All regressions include Single, Term, Single, term birth, Single $\times$ Share Public Insurance's B, C or D, ,Term $\times$ Share Public Insurance's B, $C$ or D, Single, term birth $\times$ Share Public Insurance's $B, C$ or $D$, month-year fixed effects, mother's age-year of admission fixed effects, and mother's age-county of residence fixed effects.

Standard errors, clustered by mother's county of residence, reported in brackets.

*** Significant at the 1 percent level.

** Significant at the 5 percent level.

* Significant at the 10 percent level. 
Table 7: Effect of expected hospital demand on the probability of early term birth

\begin{tabular}{lcc}
\hline & Public and Non-PAD Private Hospitals & PAD Private Hospitals \\
& $(1)$ & $(2)$ \\
\hline 25 th pctl $<$ Demand $\leq$ 50th pctl & -0.000 & 0.002 \\
& {$[0.001]$} & {$[0.002]$} \\
50 th pctl $<$ Demand $\leq 75$ th pctl & 0.000 & $0.004^{* *}$ \\
& {$[0.001]$} & {$[0.002]$} \\
Demand greater than $75 \%$ week & 0.001 & $0.006^{* * *}$ \\
& {$[0.001]$} & {$[0.001]$} \\
\hline R-squared & 0.088 & 0.113 \\
Observations & $2,353,442$ & 841,885 \\
\hline
\end{tabular}

Note: This table reports OLS estimates of expected hospital demand on early term birth (gestational age 37 or 38 weeks) for the period 2003-2016. Demand is the expected hospital demand in week $w$ of year $y$ for hospital $h$. 25th pctl $<$ Demand $\leq 50$ th pctl is a dummy that indicates if that expected demand is in the 25 to 50 percentile of the distribution of expected demand for the hospital $h$ in year $y$. Similar definitions apply for other dummies.

All regressions control for Single, Term, Single $\times$ Term, parity, mother's educational level and labor force participation, week of year fixed effects, mother's age-year fixed effects, mother's county of residence fixed effects and hospital-year fixed effects.

Standard errors, clustered by hospital, reported in brackets.

*** Significant at the 1 percent level.

** Significant at the 5 percent level.

* Significant at the 10 percent level. 
Table 8: Effect of expected hospital demand on the probability of early term birth for PAD private hospitals classified by $\mathrm{C}$-section rate intensity

\begin{tabular}{lccc}
\hline & \multicolumn{3}{c}{ PAD Private Hospitals } \\
\cline { 2 - 4 } & Low C-section rate & Intermediate C-section rate & High C-section rate \\
& $(1)$ & $(2)$ & $(3)$ \\
\hline 25th pctl $<$ Demand $\leq$ 50th pctl & -0.002 & 0.003 & $0.007^{* *}$ \\
& {$[0.003]$} & {$[0.002]$} & {$[0.003]$} \\
50 th pctl $<$ Demand $\leq 75$ th pctl & -0.001 & $0.005^{* *}$ & $0.007^{* *}$ \\
& {$[0.003]$} & {$[0.002]$} & {$[0.003]$} \\
Demand $>$ 75th pctl & 0.004 & $0.005^{* *}$ & $0.008^{* * *}$ \\
& {$[0.003]$} & {$[0.002]$} & {$[0.002]$} \\
\hline R-squared & 0.112 & 0.101 & 0.098 \\
Observations & 289,817 & 283,207 & 268,799 \\
\hline
\end{tabular}

Note: This table reports OLS estimates of expected hospital demand on early term birth (gestational age 37 or 38 weeks) for PAD private hospitals in the period 2003-2016. Demand is the expected hospital demand in week $w$ of year $y$ for hospital $h$. 25th pctl $<$ Demand $\leq 50$ th pctl is a dummy that indicates if that expected demand is in the 25 to 50 percentile of the distribution of expected demand for the hospital $h$ in year $y$. Similar definitions apply for other dummies.

The C-section rate is between 25 and $65 \%$ in low C-section rate PAD hospitals, between 65 and $77 \%$ in intermediate rate C-section rate hospitals, and over $77 \%$ in high C-section rate hospitals.

All regressions control for Single, Term, Single $\times$ Term, parity, mother's educational level and labor force participation, week of year fixed effects, mother's age-year fixed effects, mother's county of residence fixed effects and hospital-year fixed effects.

Standard errors, clustered by hospital, reported in brackets.

*** Significant at the 1 percent level.

** Significant at the 5 percent level.

* Significant at the 10 percent level. 